\title{
Co-creating health: more than a dream
}

The slow march towards true partnership with patients, which The BMJ champions, is progressing

\author{
Tessa Richards senior editor, patient partnership, Rosamund Snow patient editor, Sara Schroter \\ senior researcher
}

The BMJ, London, UK

The BMJ launched a strategy to "walk the talk" on patient partnership three years ago. ${ }^{1}$ Its key components include patient review of research papers, requiring authors to invite patients to help shape their educational articles, and new patient led content. (www.bmj.com.campaign/patient-partnership). We reported on progress a year ago. ${ }^{2}$ Since then, with the help of patient authors, our patient reviewers, and patient panel members - to all of whom we owe a debt of thanks-we have continued our ambitious quest towards coproduced content. Each section of the journal now has a target for patient involvement, and we are refining a series of research projects, including an evaluation of the strategy's impact.

In some areas, progress has been slower than we would like. One is to realise our pledge to the \#PatientsIncluded campaign to involve patients in all conferences we co-run and sponsor. But it is good to see that the campaign's call to include patients in all forums discussing their health and wellbeing is increasingly being heard, as the linked analysis by Chu et al shows. ${ }^{3}$ Patients' views on being invited to the conference table vary from enthusiastic ${ }^{4-6}$ to sceptical. ${ }^{7}$ This is not surprising. It is hard to ensure that patient participation is more than tokenistic. Conference organisers need to model partnership from the outset, starting with appointing patients on to the committees that steer events.

Involving patients in setting research priorities has potential to reduce waste in the research enterprise, ${ }^{8}$ and The BMJ now requires all authors submitting research papers to include a statement detailing if and how they included patients in their work.(http://www.bmj.com/about-bmj/resources-authors/articletypes/research). Eventually, we hope to adopt a policy where we will only publish clinical research that has been coproduced. Ioannidis argues that the value of research increases when patients are "savvy about science in the making and protected from biased influences." "This is worth noting. Pharma companies regularly invite patients to meetings, and many have patient groups to inform research and development. The imperative now is to identify and disseminate best practice so that patient involvement in drug research and development delivers outcomes that patients value. ${ }^{10}{ }^{11}$ The European Medicines Agency ${ }^{12}$ and US Food and Drug Agency are also prioritising patient involvement and are collaborating on how best to achieve it.

Many organisations and foundations who fund research already embrace patient involvement and public engagement, including the Patient Centred Outcomes Research Institute, the National Institute for Health Research, and the Canadian Institutes for Health Research. Here too the challenge is to identify and implement meaningful partnership, and to assess its effect ${ }^{13}$ on improving healthcare through better targeted research funding, outcomes that matter to patients, and a more patient oriented research agenda.

Patient involvement in strategies to improve the design, delivery, and quality of care has become routine in some settings, although "involvement" usually falls well short of partnership. The patient and carer advisory groups set up by UK hospitals, general practices, and the royal colleges tend to operate in the margins with an agenda primarily set by staff; and once again, evidence assessing their effect is weak. ${ }^{14}$ The value of patient feedback is also limited since quantity of data has trumped quality. ${ }^{15}$ A smaller and more manageable volume of higher quality data, combined with timely and personal interaction and feedback would be preferable; PatientOpinion.org.uk, an online way of giving feedback about your care to NHS trusts, is a good example.

Encouragingly, shared decision making, the cornerstone of partnership and patient centred care is beginning to show modest signs of moving from policy imperative to routine practice. ${ }^{16}$ There is also a move towards partnership in undergraduate medical education ${ }^{17}$ as universities respond to the General Medical Council's request for patient involvement in admissions, teaching, curriculum design, assessment, and governance. ${ }^{18}$

Employing patient leaders to drive engagement and partnership within the formal structure of the health service is the next logical step, and in July The BMJ heard from pioneer David Gilbert, who is the first patient director in the NHS. His experience at the Sussex Musculoskeletal Partnership and the response to it should surely encourage other services to follow suit. $^{19}$ 
Patients and their organisations have clear views on their role in coproducing health and wellbeing. ${ }^{20}$ The new digital technologies, medical devices, and apps they are being encouraged to use could help advance partnership as well as promote self management. The promise of open access to fully integrated electronic health records also needs to be realised, and the conversations patients have in their online communities must be brought closer to the conversations currently conducted among health professionals. Health professionals should also give higher priority to patient partnership and patient centred care in routine clinical practice. The development of new patient oriented quality indicators to encourage and reward those who do will help. ${ }^{21}$

Meanwhile, in the rarefied world of medical publishing, it's good to see other journals following The BMJ's lead. ${ }^{22}$ The growing support for a new charter for journals on \#PatientsIncluded ${ }^{23}$ will, we hope, spur others to follow suit.

Competing interests: We have read and understood BMJ policy on declaration of interests and declare TR and RS lead The BMJs patient partnership strategy and SS is conducting research to evaluate its progress.

Provenance and peer review: Commissioned; not externally peer reviewed.

1 Richards T, Montori VM, Godlee F, Lapsley P, Paul D. Let the patient revolution begin. BMJ 2013;346:f2614. doi:10.1136/bmj.f2614 pmid:23674136.

2 Richards T, Snow R, Schroter S. Logging The BMJ's "patient journey". BMJ 2015;351:h4396. doi:10.1136/bmj.h4396 pmid:26283221.

3 Chu LF, Utengen A, Kadry B. "Nothing about us without us"-patient partnership in medical conferences. BMJ 2016;354:i3883.

4 EULAR 2016: Q\&A, 27 Jun 2016.https://creakyjoints.org/blog/eular-2016-qa/
5 Betteridge N. Effective involvement of patients at medical meetings: a case study. $14 \mathrm{Sep}$ 2016. http://blogs.bmi.com/bmj/2016/09/14/effective-involvement-of-patients-medicalmeetings-a-case-study

6 European Lung Foundation. Patient involvement in the European Respiratory Society Congress. 14 Sep 2016. http://blogs.bmj.com/bmj/2016/09/14/patient-involvement-in-theeuropean-respiratory-society-congress

7 Price A. The evidence informed patient. 14 Sep 2016. http://blogs.bmj.com/bmj/2016/09/ 14/amy-price-the-evidence-informed-patient/

8 Chalmers I, Bracken MB, Djulbegovic B, et al. How to increase value and reduce waste when research priorities are set. Lancet 2014;383:156-65. doi:10.1016/S0140-6736(13) 62229-1 pmid:24411644.

9 Ioannidis JPA. Why most clinical research is not useful. PLoS Med 2016;13:e1002049. doi:10.1371/journal.pmed.1002049 pmid:27328301.

10 Hoos A, Anderson J, Boutin M, et al. Partnering with patients in the development and lifecycle of medicines: a call for action. Ther Innov Regul Sci 2015;49:929-39. doi:10.1177/ 2168479015580384. pmid:26539338.

11 Lowe MM, Blaser DA, Cone L, et al. Increasing patient involvement in drug development. Value in Healthcare, 2016, 10.1016/j.jval.2016.04.009.

12 European Medicines Agency. EMA celebrates ten years of its patients and consumers working party. 10 Jun 2016. [http://www.ema.europa.eu/ema/index.jsp?curl=pages/news and_events/news/2016/06/news_detail_002548.jsp\&mid=WC0b01ac058004d5c1

13 Torjesen I. Public involvement in research should be "second nature" by 2025, review concludes. BMJ 2015;350:h1913. doi:10.1136/bmj.h1913 pmid:25858256.

14 Mockford C, Staniszewska S, Griffiths F, Herron-Marx S. The impact of patient and public involvement on UK NHS health care: a systematic review. Int J Qual Health Care 2012;24:28-38. doi:10.1093/intghc/mzr066 pmid:22109631.

15 Coulter A. Patient feedback for quality improvement in general practice. $B M J$ 2016;352:i913. doi:10.1136/bmj.i913 pmid:26893467.

16 Coulter A. At last some better news on shared decision making. 1 Jul 2016. http://blogs. bmj.com/bmj/2016/07/01/angela-coulter-at-last-some-better-news-on-shared-decisionmaking/

17 Lived Experience Network. http://www.alps-cetl.ac.uk/len.htm

18 GMC. Patient and public involvement in undergraduate medical education. http://www. gmc-uk.org/Patient_and_public_involvement_in_undergraduate_medical_education_ guidance_under_review_0815.pdf_56438926.pdf

19 Five minutes with David Gilbert, patient director. BMJ 2016;354:i3689.pmid:27385326.

20 European Patients Forum. Charter on patient empowerment. http://www.eu-patient.eu/ campaign/patientsprescribe/charter-on-patient-empowerment/)

21 Steel N, Shekelle P. After 12 years, where next for QOF?BMJ 2016;354:14103. doi:10. 1136/bmj.i4103 pmid:27492773.

22 Research Involvement and Engagement https://researchinvolvement.biomedcentral.com/

23 Patients Included. Journals charter, 2016. https://patientsincluded.org/journals/

Published by the BMJ Publishing Group Limited. For permission to use (where not already granted under a licence) please go to http://group.bmj.com/group/rights-licensing/ permissions 